\title{
High-intensity interval or circuit-based strength training effects on physical and cognitive functioning for community-dwelling older adults: A systematic review protocol.
}

\author{
Ashley Morgan, ${ }^{1}$ Kenneth S Noguchi, ${ }^{1}$ Ada Tang, ${ }^{1}$ Jennifer Heisz, ${ }^{2}$ Lehana Thabane, ${ }^{3}$ Julie \\ Richardson $^{1}$
}

\begin{abstract}
Background: High-intensity interval or circuit-based strength training utilizes brief intense periods of strengthening exercises interspersed with rest/light activity or performed in a continuous circuit. The physical and cognitive effects of this time-efficient approach in community-dwelling older adults have not been systematically reviewed.
\end{abstract}

Objectives: To determine the effects of high-intensity interval or circuit-based strength training interventions on physical and cognitive functioning for community-dwelling older adults, and the associated adherence, retention, and adverse event rates.

Methods: Six databases will be searched from inception to November 2021; MEDLINE, EMBASE, CINAHL, AgeLine, SPORTDiscus, and Web of Science. To assess physical and/or cognitive functioning effects, randomized and quasi-randomized controlled trials (RCTs and QRCTs) of high-intensity interval or circuit-based strengthening interventions in communitydwelling older adults, utilizing any comparator, will be included. The above criteria will be extended to include non-randomized study designs to assess adherence, retention, and adverse events. All screening, data extraction and risk of bias will be assessed by two independent reviewers. Risk of bias will be assessed utilizing the Cochrane RoB 2 tool for randomized and ROBINS-I for non-randomized studies. Qualitative synthesis will be used to present information on adherence, retention, and adverse event rates. Qualitative and/or quantitative synthesis will be used to present physical and cognitive functioning effects depending on which method is deemed appropriate for the various outcomes.

Conclusion: This systematic review will be the first to summarize the physical and/or cognitive effects, adherence, retention, and adverse events reported in high-intensity interval and circuitbased strengthening interventions for community-dwelling older adults.

\section{Systematic review registration number: CRD42021284010}

Keywords: older adults; high-intensity exercise; physical functioning; cognitive functioning Abstract word count: 249 Total manuscript word count: 2132

\footnotetext{
${ }^{1}$ School of Rehabilitation Sciences, McMaster University, Hamilton, Ontario, Canada

${ }^{2}$ Department of Kinesiology, McMaster University, Hamilton, Ontario, Canada

${ }^{3}$ Department of Health Research Methods, Evidence, and Impact (HEI), McMaster University, Hamilton, Ontario, Canada Corresponding Author: Dr. Julie Richardson, School of Rehabilitation Sciences, McMaster University, Institute of Applied Health Sciences, 1400 Main Street West, Hamilton, Ontario, Canada, LSC 1C7. jrichard@mcmaster.ca
} 


\section{Introduction}

Despite the recognized benefits of exercise on physical [1-5] and cognitive functioning [1,6-8] for older adults, only one third of older Canadians accumulate the recommended 150 minutes of moderate to vigorous physical activity per week [9]. The World Health Organization recommends older adults perform at least 150 minutes of moderate-intensity or 75 minutes vigorous-intensity aerobic activity per week or an equivalent combination, as well as the inclusion of strengthening exercises at least two days per week [10]. High-intensity interval or circuit-based strength training may offer a time-efficient form of exercise to address these recommendations.

Evidence suggests that exercise intensity may impact outcomes on physical [11] and cognitive functioning [12] in older adults. In older adults, recent systematic reviews found highintensity aerobic activity demonstrates equivalent or superior effects on cardiovascular fitness compared with moderate intensity despite its' shorter duration [11] and may facilitate greater improvements in working memory [12]. A systematic review of 56 meta-analyses of various exercise interventions for older adults reported that resistance training had the largest effect sizes overall, including for physical functioning [1], and other reviews suggest that higher intensity resistance training is superior to low intensity for improvements in strength $[2,13]$ and aerobic capacity [2].

High-intensity interval training (HIIT), which combines brief intense bouts of aerobic activity combined with rest or low intensity exercise [14] is recognized as an efficient and effective mode of exercise with evidence supporting cardiovascular benefits and safety for older adults. 
[11]. An analogous high-intensity interval or circuit-based format has also been applied for strengthening exercises [15-17], employing various descriptors; including, "high intensity interval in circuit training (HIICT)"'[15] "high-intensity interval resistance training (HIRT)" and "high-intensity functional training (HIFT)" [18]. Through an interval or circuit format, strengthening exercises are performed at a high-intensity (relative to ability) with no or minimal rest, thereby also offering potential aerobic benefits [18]. Randomized controlled trials of highintensity strength training using an interval or circuit-based format in older women have demonstrated improvements in walking speed [17] and speed of chair stands [16]. A 12-week quasi-randomized trial in older adults also found benefits on leg extensor strength, cardiorespiratory fitness (predicted maximal oxygen consumption [VO2max]) and reported all 18 participants in the high-intensity group completed the intervention with an overall attendance of $99 \%$ [19]. Despite the potential benefits, this type of exercise has received less attention than HIIT and the current evidence on the effects of high-intensity interval or circuit-based has not been systematically reviewed. The purpose of this review of this systematic review is to answer the following questions;

\section{Questions addressed by Systematic Review}

1. What are the effects of high-intensity interval or circuit-based strength training interventions on physical and cognitive functioning for community-dwelling older adults? and,

2. What are the reported adherence, retention, and adverse event rates for these interventions?

\section{Materials and Methods}


This protocol follows the Preferred Reporting Items for Systematic Reviews and Meta-Analysis Protocols (PRISMA-P)[20] (see Appendix I). This protocol is registered with the International prospective register of systematic reviews (PROSPERO), registration number;

CRD42021284010.

\section{Inclusion criteria}

\section{Study Design}

To determine effects of high-intensity interval or circuit-based strength training on physical and cognitive functioning, randomized controlled trials (RCTs) and quasi-randomized controlled trials (Q-RCT; allocation method not random e.g., alternation, day of week, etc.,) [21] will be included. To assess the reported adherence, retention, and adverse event rates, other nonrandomized study designs, specifically nonrandomized controlled trial (NRCT), controlled before-and-after (CBA), and before and after (BA) studies [21] will also be included.

Nonrandomized studies are prone to greater bias than RCTs but can be particularly useful in providing information regarding harms, especially when evidence from RCTs may be limited [22-24]. Grey literature will not be included.

\section{Participants}

Eligible participants will be community-dwelling older adults. Study samples must have a mean or median age of 60 years or older. Studies focused on samples of older adults with moderate/severe cognitive impairment (clinical diagnosis of dementia or Alzheimer's disease or indicated by cognitive screening tool such as Montreal Cognitive Assessment or Mini Mental State Exam), a neurological condition or pre- or post-surgery will be excluded. Studies with mixed populations of older adults will be excluded if $>50 \%$ of the sample includes individuals 
with moderate/severe cognitive impairment (see previous criteria previously), a neurological condition or are pre- or post-surgery.

\section{Interventions}

Eligible interventions will be $\geq 4$ weeks in total duration. Eligible interventions will involve strengthening exercises (including body weight and external resistance) that are performed in a continuous circuit (i.e., several exercises performed sequentially with no/minimal rest between exercises, may have rest between circuits)[25-27] or interval format (alternating periods of time performing high intensity exercise with periods of low intensity activity or rest[28]). Highintensity must be defined using prespecified target criteria (e.g., rating of perceived exertion, percentage of heart rate or one-repetition maximum). Acceptable criteria may include; $\geq 80 \%$ peak/maximum heart rate (PHR/MHR)[29], heart rate reserve (HHR)[30] peak work rate (PWR)[29], or maximal oxygen consumption (VO2 max)[30]; $\geq 70 \%$ one-repetition maximum (1RM); or $\geq 14 / 20$ using Borg's rating of perceived exertion scale [31,32] (or the equivalent of at least "hard" using another scale). Inclusion of a familiarization period (not meeting highintensity criteria) is acceptable; however, this duration should not exceed $1 / 3$ of the total intervention duration. Interventions which combine high-intensity interval or circuit-based strength training with other additional interventions likely to impact physical and/or cognitive functioning (e.g., cognitive training, other forms of exercise) will be excluded. 'Other forms of exercise' will be considered the inclusion of exercise components beyond a warm-up and cooldown period (e.g., high-intensity strength circuit followed by 30 minutes stationary cycling).

\section{Comparators}

To assess effects on the intervention on physical and/or cognitive functioning, studies comparing interval or circuit-based high-intensity strength training to a control group or intervention that 
does not include interval or circuit-based high-intensity strength training will be included. To assess adherence, retention, and adverse event rates, studies utilizing any or no comparator intervention will be included.

\section{Outcomes}

Eligible studies will be included if effects of the intervention on any specified physical or cognitive functioning outcome are included. Physical functioning outcomes will include measures of both physiological impairment; specifically measures assessing muscle strength or cardiorespiratory fitness, and measures of mobility and performance capacity [33] (e.g., selfreport questionnaires, performance of functional tasks including walking and sit to stands). Cognitive functioning outcomes will include any measures which assess general cognition or specific domains/functions. Studies which only report acute effects (immediately after a single bout of exercise) will be excluded.

\section{Setting}

Any setting will be included provided the older adults are living in the community.

\section{Language}

Studies published in English will be included.

\section{Search strategy}

Six databases will be searched with no date restrictions to October 2021: Ovid MEDLINE, Ovid EMBASE, EBSCOhost CINAHL, EBSCOhost AgeLine, EBSCOhost SPORTDiscus, and Clarivate Web of Science. A McMaster University research librarian assisted in the development and refinement of the MEDLINE search strategy which can be found in Appendix II. This strategy with feedback from the research librarian was adapted for each database listed above. Searches will be re-run in all databases in November 2021 to identify any 
medRxiv preprint doi: https://doi.org/10.1101/2022.02.10.22270669; this version posted February 10, 2022. The copyright holder for this preprint (which was not certified by peer review) is the author/funder, who has granted medRxiv a license to display the preprint in perpetuity.

All rights reserved. No reuse allowed without permission.

additional studies. Finally, the references list of relevant studies will be hand-searched to identify additional studies.

\section{Data Management}

Titles and abstracts of eligible articles will be uploaded to Covidence systematic review management software [34] for screening. After initial title and abstract screening, full text for eligible articles will be retrieved and uploaded into Covidence to assess against inclusion and exclusion criteria. The final data extraction phase will utilize Microsoft Excel software [35].

\section{Study Selection}

Detailed inclusion and exclusion criteria will be provided to reviewers, titles and abstracts of articles will be screened independently by two reviewers (AM and $\mathrm{KN}$ ), after a calibration period. This period will involve both reviewers independently screening 20 titles and abstracts to ensure inclusion and exclusion is understood. Articles that appear to meet inclusion criteria or are uncertain will be included at this stage. These articles will be retrieved in full text and will be screened independently by two reviewers (AM and $\mathrm{KN}$ ) after a similar calibration period. Any disagreement will be resolved through discussion or consultation with a third reviewer (JR). Additional information will be sought from authors as needed. Reviewers will not be blind to study title or author(s).

\section{Data extraction}

Piloted standardized data extraction forms will be used to extract data from each eligible article by two independent reviewers (AM and $\mathrm{KSN}$ ). The data extraction forms found in Appendix III detail the variables for which data will be sought and these forms will be pilot tested with at least five articles to ensure completeness and clarity.

\section{Risk of Bias Assessment}


medRxiv preprint doi: https://doi.org/10.1101/2022.02.10.22270669; this version posted February 10, 2022. The copyright holder for this preprint

(which was not certified by peer review) is the author/funder, who has granted medRxiv a license to display the preprint in perpetuity.

All rights reserved. No reuse allowed without permission.

Risk of bias for RCTs will be assessed using the revised Cochrane Risk of Bias (RoB 2) [36] tool. Non-randomized studies will be assessed using the Risk Of Bias in Non-randomised Studies-of Interventions (ROBINS-I) [37]. Two independent reviewers (AM and KSN) will conduct risk of bias assessments, with any disagreements resolved through discussion or consultation with a third reviewer (JR). Reviewers will not be blinded to article title or author(s).

\section{Data synthesis}

The study characteristics reported in included studies will be summarized and compared to determine where synthesis may be appropriate. Study authors will be contacted to obtained insufficient or missing information. Information on the effects of the intervention on physical and cognitive outcomes will be collected from RCTs and quasi-RCTs. Information on adherence, retention, and adverse events will also be collected from the additional non-randomized designs specified in the inclusion criteria. Randomized controlled trials will not be combined with nonrandomized study designs for synthesis. Qualitative synthesis, utilizing text and tables, will be used to present information on adherence, retention, and adverse event rates and intervention characteristics (e.g., exercise parameters, duration). Data on the effects on physical and cognitive functioning outcomes will be grouped according to shared outcomes (e.g., muscle strength, gait speed, general cognition, etc.,) and presented using qualitative and/or quantitative synthesis depending on which method is deemed appropriate for the various outcomes.

Quantitative synthesis (meta-analysis) will be conducted based on considerations of clinical, methodological, and statistical heterogeneity. Clinical heterogeneity considers variability in the intervention and comparators, population characteristics, outcomes and followup duration[38] while methodological heterogeneity considers study design, measurement tools, and risk of bias. Clinical and methodological heterogeneity will impact statistical heterogeneity 
(variability in intervention effects). For those studies deemed suitable to combine based on clinical and methodological considerations; statistical heterogeneity will be quantified using the chi squared and $\mathrm{I}^{2}$ tests. An $\mathrm{I}^{2}$ statistic of $50-90 \%$ may represent substantial, and $75-100 \%$ considerable heterogeneity [38]. Combined studies with an $\mathrm{I}^{2}$ statistic of $\geq 75 \%$ will not be combined and those with 50-75\% will consider the size and direction and effects and the strength of the evidence for heterogeneity (e.g., confidence interval for $\mathrm{I}^{2}, \mathrm{p}$-value from chi-squared test) [38].

If appropriate, meta-analysis will be conducted using the mean difference for outcomes utilizing the same scale and standardized mean difference for those utilizing different scales [38]. Results will be presented with $95 \%$ confidence intervals. Missing standard deviation values will be estimated using standard errors, confidence intervals, $\mathrm{t}$ values, and/or $\mathrm{P}$ values based on the recommendations from the Cochrane handbook [38]. Data will be used from intention-to-treat analysis data if available. A random effects model will be used for any meta-analyses. If deemed appropriate for combination, subgroup analyses will be conducted based on intervention (criteria utilized for "high-intensity"; duration $<12$ weeks, $\geq 12$ weeks) and sample characteristics (clinical conditions, sex). Credibility of subgroup analyses will be assessed using the Instrument to assess the Credibility of Effect Modification Analyses (ICEMAN)[39]. Sensitivity analysis will be conducted removing studies with high risk of bias.

\section{Assessing certainty of findings}

The certainty of findings for intervention effects on physical and cognitive outcomes will be assessed using the Grading of Recommendations Assessment, Development and Evaluation (GRADE) [40] approach resulting a rating of high, moderate, low, or very low quality. GRADE summary of findings (SoF) tables will be used to summarize the results. The recommendations 
from the GRADE working group will be followed regarding the evaluation and incorporation of non-randomized studies into rating the certainty of a body of evidence[41], including rating the certainty of evidence for RCTs and quasi-RCTs separately.

\section{Discussion}

High-intensity interval or circuit-based strength training may offer a time-efficient approach to exercise. However, existing evidence on the effects on community-dwelling older adults' physical and cognitive functioning has yet to be systematically reviewed. Information summarizing the retention, adherence, and adverse events rates for interventions employing this type of training in older adult populations is also required. The results of this review will present valuable considerations for alternative training approaches and optimizing exercise prescription for community-dwelling older adults. High-intensity strength training using an interval or circuitbased format is an emerging area of research and this review will summarize the current evidence and recommend important future directions.

Funding details: This works was not supported by any funding or grant-awarding bodies.

Disclosure: The authors report there are no competing interests to declare. 


\section{References}

1. Di Lorito C, Long A, Byrne A, Harwood RH, Gladman JRF, Schneider S, et al. Exercise interventions for older adults: A systematic review of meta-analyses. J Sport Heal Sci [Internet]. 2021;10(1):29-47. Available from: https://doi.org/10.1016/j.jshs.2020.06.003

2. Liu CJ, Latham NK. Progressive resistance strength training for improving physical function in older adults. Cochrane Database Syst Rev. 2009;(3):1-212.

3. Bangsbo J, Blackwell J, Boraxbekk CJ, Caserotti P, Dela F, Evans AB, et al. Copenhagen Consensus statement 2019: Physical activity and ageing. Br J Sports Med. 2019 Jul $1 ; 53(14): 856-8$.

4. Liu C ju, Shiroy DM, Jones LY, Clark DO. Systematic review of functional training on muscle strength, physical functioning, and activities of daily living in older adults. Eur Rev Aging Phys Act. 2014 Oct 1;11(2):95-106.

5. Liberman K, Forti LN, Beyer I, Bautmans I. The effects of exercise on muscle strength, body composition, physical functioning and the inflammatory profile of older adults: A systematic review. Curr Opin Clin Nutr Metab Care. 2017;20(1):30-53.

6. Gomes-Osman J, Cabral DF, Morris TP, McInerney K, Cahalin LP, Rundek T, et al. Exercise for cognitive brain health in aging: A systematic review for an evaluation of dose. Neurol Clin Pract. 2018 Jun 1;8(3):257-65.

7. Quigley A, MacKay-Lyons M, Eskes G. Effects of Exercise on Cognitive Performance in Older Adults: A Narrative Review of the Evidence, Possible Biological Mechanisms, and Recommendations for Exercise Prescription. J Aging Res. 2020;2020.

8. Bherer L, Erickson KI, Liu-Ambrose T. A Review of the Effects of Physical Activity and Exercise on Cognitive and Brain Functions in Older Adults. J Aging Res [Internet]. 
2013;2013:1-8. Available from: http://www.hindawi.com/journals/jar/2013/657508/

9. Statistics Canada. Canadian Health Measures Survey: Activity monitor data, 2018-2019.

The Daily. 2021.

10. World Health Organization. Global recommendations on Physical Activity for Health. Geneva, Switzerland; 2010.

11. Keating CJ, Párraga Montilla JÁ, Latorre Román PÁ, Moreno del Castillo R. Comparison of High-Intensity Interval Training to Moderate-Intensity Continuous Training in Older Adults: A Systematic Review. J Aging Phys Act. 2020 Apr 17;1-10.

12. Hsieh SS, Chueh TY, Huang CJ, Kao SC, Hillman CH, Chang YK, et al. Systematic review of the acute and chronic effects of high-intensity interval training on executive function across the lifespan. J Sports Sci [Internet]. 2021;39(1):10-22. Available from: https://doi.org/10.1080/02640414.2020.1803630

13. Raymond MJ, Bramley-Tzerefos RE, Jeffs KJ, Winter A, Holland AE. Systematic review of high-intensity progressive resistance strength training of the lower limb compared with other intensities of strength training in older adults. Arch Phys Med Rehabil. 2013 Aug;94(8):1458-72.

14. Gibala MJ, Little JP, Macdonald MJ, Hawley JA. Physiological adaptations to lowvolume, high-intensity interval training in health and disease. J Physiol. 2012 Feb;590(5):1077-84.

15. Ballesta-García I, Martínez-González-moro I, Rubio-Arias J, Carrasco-Poyatos M. Highintensity interval circuit training versus moderate-intensity continuous training on functional ability and body mass index in middle-aged and older women: A randomized controlled trial. Int J Environ Res Public Health. 2019 Nov 1;16(21):4205. 
16. Nunes PRP, Martins FM, Souza AP, Carneiro MAS, Nomelini RS, Michelin MA, et al. Comparative effects of high-intensity interval training with combined training on physical function markers in obese postmenopausal women: A randomized controlled trial.

Menopause J North Am Menopause Soc. 2019 Nov 1;26(11):1242-9.

17. Martins FM, de Paula Souza A, Nunes PRP, Michelin MA, Murta EFC, Resende EAMR, et al. High-intensity body weight training is comparable to combined training in changes in muscle mass, physical performance, inflammatory markers and metabolic health in postmenopausal women at high risk for type 2 diabetes mellitus: A randomized controlled cl. Exp Gerontol. 2018 Jul 1;107:108-15.

18. Feito Y, Heinrich K, Butcher S, Poston W. High-Intensity Functional Training (HIFT): Definition and Research Implications for Improved Fitness. Sports. 2018 Aug 7;6(3):76.

19. Hurst C, Weston KL, Weston M. The effect of 12 weeks of combined upper- and lowerbody high-intensity interval training on muscular and cardiorespiratory fitness in older adults. Aging Clin Exp Res. 2019 May 3;31(5):661-71.

20. Shamseer L, Moher D, Clarke M, Ghersi D, Liberati A, Petticrew M, et al. Preferred reporting items for systematic review and meta-analysis protocols (prisma-p) 2015: Elaboration and explanation. BMJ [Internet]. 2015;349(January):1-25. Available from: http://dx.doi.org/doi:10.1136/bmj.g7647

21. Reeves BC, Wells GA, Waddington H. Quasi-experimental study designs series_paper 5: a checklist for classifying studies evaluating the effects on health interventions-a taxonomy without labels. J Clin Epidemiol [Internet]. 2017;89:30-42. Available from: https://doi.org/10.1016/j.jclinepi.2017.02.016

22. Sterne JAC, Hernán MA, Reeves BC, Savović J, Berkman ND, Viswanathan M, et al. The 
Risk Of Bias In Non-randomized Studies of Interventions ( ROBINS-I ). Bmj. 2016;355:i4919.

23. Reeves BC, Deeks JJ, Higgins JP, Shea B, Tugwell P, Wells GA. Including nonrandomized studies on intervention effects. In: Higgins JP, Thomas J, Chandler J, Cumpston M, Li T, Page MJ, et al., editors. Cochrane Handbook for Systematic Reviews of Interventions, Second Edition. Chichester, UK: John Wiley and Sons Ltd; 2019. p. 595-620.

24. Reeves BC, Higgins JPT, Ramsay C, Shea B, Tugwell P, Wells GA. An introduction to methodological issues when including non-randomised studies in systematic reviews on the effects of interventions. Res Synth Methods. 2013;4(1):1-11.

25. Romero-Arenas S, Martínez-Pascual M, Alcaraz PE. Impact of resistance circuit training on neuromuscular, cardiorespiratory and body composition adaptations in the elderly. Aging Dis. 2013;4(5):256-63.

26. Ramos-Campo DJ, Caravaca LA, Martínez-Rodríguez A, Rubio-Arias JÁ. Effects of resistance circuit-based training on body composition, strength and cardiorespiratory fitness: A systematic review and meta-analysis. Biology (Basel). 2021;10(5).

27. American College of Sports Medicine. Progression models in resistance training for healthy adults. Med Sci Sports Exerc. 2009;41(3):687-708.

28. Hough P. High-intensity interval training. Am Coll Sport Med Heal Fit J. 2014;18(5):116.

29. Weston KS, Wisløff U, Coombes JS. High-intensity interval training in patients with lifestyle-induced cardiometabolic disease: A systematic review and meta-analysis. Br J Sports Med. 2014;48(16):1227-34. 
30. Martland R, Mondelli V, Gaughran F, Stubbs B. Can high-intensity interval training improve physical and mental health outcomes? A meta-review of 33 systematic reviews across the lifespan. J Sports Sci. 2020 Feb 16;38(4):430-69.

31. Row BS, Knutzen KM, Skogsberg NJ. Regulating Explosive Resistance Training Intensity Using the Rating of Perceived Exertion. J Strength Cond Res. 2012;26(3):664-71.

32. Winett RA, Ogletree AM. Evidence-Based, High-Intensity Exercise and Physical Activity for Compressing Morbidity in Older Adults: A Narrative Review. Innov Aging. 2019 May $1 ; 3(4): 1-15$.

33. Painter P, Marcus RL. Assessing physical function and physical activity in patients with CKD. Clin J Am Soc Nephrol. 2013;8(5):861-72.

34. Covidence systematic review software [Internet]. Melbourne, Australia: Veritas Health Innovation; 2021. Available from: covidence.org

35. Microsoft. Microsoft Excel for Microsoft 365. Redmond, Washington.

36. Sterne J, Savović J, Page M, Elbers R, Blencowe N, Boutron I, et al. RoB 2: a revised tool for assessing risk of bias in randomised trials. Br Med J [Internet]. 2019;366(I4898). Available from: https://methods.cochrane.org/bias/resources/rob-2-revised-cochrane-riskbias-tool-randomized-trials

37. Sterne JA, Hernán MA, Reeves BC, Savović J, Berkman ND, Viswanathan M, et al. ROBINS-I: A tool for assessing risk of bias in non-randomised studies of interventions.

BMJ. 2016;355(i4919).

38. Higgins JPT, Thomas J, Chandler J, Cumpston M, Li T, Page MJ, et al. Cochrane handbook for systematic reviews of interventions. Cochrane Handbook for Systematic Reviews of Interventions. 2019. 1-694 p. 
medRxiv preprint doi: https://doi.org/10.1101/2022.02.10.22270669; this version posted February 10, 2022. The copyright holder for this preprint

(which was not certified by peer review) is the author/funder, who has granted medRxiv a license to display the preprint in perpetuity.

All rights reserved. No reuse allowed without permission.

39. Schandelmaier S, Briel M, Varadhan R, Schmid CH, Devasenapathy N, Hayward RA, et al. Development of the instrument to assess the credibility of effect modification analyses (ICEMAN) in randomized controlled trials and meta-analyses. Cmaj. 2020;192(32):E9016.

40. Guyatt GH, Oxman AD, Vist GE, Kunz R, Falck-Ytter Y, Alonso-Coello P, et al. GRADE: An emerging consensus on rating quality of evidence and strength of recommendations. BMJ. 2008;336(26 April):924-6.

41. Schünemann HJ, Cuello C, Akl EA, Mustafa RA, Meerpohl JJ, Thayer K, et al. GRADE guidelines: 18. How ROBINS-I and other tools to assess risk of bias in nonrandomized studies should be used to rate the certainty of a body of evidence. J Clin Epidemiol. 2019;111(2019):105-14. 
Appendix I: PRISMA-P checklist

\section{PRISMA-P (Preferred Reporting Items for Systematic review and Meta-Analysis Protocols) 2015 checklist: recommended items to address in a systematic review protocol*}

\begin{tabular}{|c|c|c|}
\hline Section and topic & Item No & Checklist item \\
\hline \multicolumn{3}{|c|}{ ADMINISTRATIVE INFORMATION } \\
\hline \multicolumn{3}{|l|}{ Title: } \\
\hline Identification & $1 \mathrm{a}$ & $\begin{array}{l}\text { Identify the report as a protocol of a systematic review } \\
\text { Title and Abstract }\end{array}$ \\
\hline Update & $1 b$ & If the protocol is for an update of a previous systematic review, identify as such \\
\hline Registration & 2 & $\begin{array}{l}\text { If registered, provide the name of the registry (such as PROSPERO) and } \\
\text { registration number } \\
\text { Abstract, PAGE } 3\end{array}$ \\
\hline \multicolumn{3}{|l|}{ Authors: } \\
\hline Contact & $3 a$ & $\begin{array}{l}\text { Provide name, institutional affiliation, e-mail address of all protocol authors; } \\
\text { provide physical mailing address of corresponding author } \\
\text { Title page }\end{array}$ \\
\hline Contributions & $3 b$ & $\begin{array}{l}\text { Describe contributions of protocol authors and identify the guarantor of the } \\
\text { review }\end{array}$ \\
\hline Amendments & 4 & $\begin{array}{l}\text { If the protocol represents an amendment of a previously completed or published } \\
\text { protocol, identify as such and list changes; otherwise, state plan for documenting } \\
\text { important protocol amendments }\end{array}$ \\
\hline
\end{tabular}

\begin{tabular}{lll}
$\begin{array}{l}\text { Support: } \\
\text { Sources }\end{array}$ & $5 a$ & $\begin{array}{l}\text { Indicate sources of financial or other support for the review } \\
\text { N/A }\end{array}$ \\
$\begin{array}{l}\text { Sponsor } \\
\begin{array}{l}\text { Role of sponsor or } \\
\text { funder }\end{array}\end{array}$ & $5 \mathrm{~b}$ & $\begin{array}{l}\text { Provide name for the review funder and/or sponsor } \\
\text { Describe roles of funder(s), sponsor(s), and/or institution(s), if any, in developing } \\
\text { the protocol }\end{array}$ \\
\hline
\end{tabular}

\section{INTRODUCTION}

\begin{tabular}{lcl}
\hline Rationale & 6 & $\begin{array}{l}\text { Describe the rationale for the review in the context of what is already known } \\
\text { PAGE 1-2 }\end{array}$ \\
\hline Objectives & 7 & $\begin{array}{l}\text { Provide an explicit statement of the question(s) the review will address with } \\
\text { reference to participants, interventions, comparators, and outcomes (PICO) } \\
\text { PAGE 2 }\end{array}$ \\
\hline METHODS & 8 & $\begin{array}{l}\text { Specify the study characteristics (such as PICO, study design, setting, time frame) } \\
\text { and report characteristics (such as years considered, language, publication status) } \\
\text { to be used as criteria for eligibility for the review } \\
\text { PAGE 3-5 }\end{array}$ \\
\hline Eligibility criteria & 9 & $\begin{array}{l}\text { Describe all intended information sources (such as electronic databases, contact } \\
\text { with study authors, trial registers or other grey literature sources) with planned } \\
\text { dates of coverage } \\
\text { PAGE 5-6 }\end{array}$ \\
\hline Information sources & 10 & $\begin{array}{l}\text { Present draft of search strategy to be used for at least one electronic database, } \\
\text { including planned limits, such that it could be repeated }\end{array}$ \\
\hline Search strategy &
\end{tabular}




\begin{tabular}{|c|c|c|}
\hline & & APPENDIX II \\
\hline \multicolumn{3}{|l|}{ Study records: } \\
\hline Data management & $11 a$ & $\begin{array}{l}\text { Describe the mechanism(s) that will be used to manage records and data } \\
\text { throughout the review } \\
\text { PAGE } 6\end{array}$ \\
\hline Selection process & $11 b$ & $\begin{array}{l}\text { State the process that will be used for selecting studies (such as two independent } \\
\text { reviewers) through each phase of the review (that is, screening, eligibility and } \\
\text { inclusion in meta-analysis) } \\
\text { PAGE } 6\end{array}$ \\
\hline $\begin{array}{l}\text { Data collection } \\
\text { process }\end{array}$ & $11 \mathrm{c}$ & $\begin{array}{l}\text { Describe planned method of extracting data from reports (such as piloting forms, } \\
\text { done independently, in duplicate), any processes for obtaining and confirming } \\
\text { data from investigators } \\
\text { PAGE } 6\end{array}$ \\
\hline Data items & 12 & $\begin{array}{l}\text { List and define all variables for which data will be sought (such as PICO items, } \\
\text { funding sources), any pre-planned data assumptions and simplifications } \\
\text { APPENDIX III }\end{array}$ \\
\hline $\begin{array}{l}\text { Outcomes and } \\
\text { prioritization }\end{array}$ & 13 & $\begin{array}{l}\text { List and define all outcomes for which data will be sought, including prioritization } \\
\text { of main and additional outcomes, with rationale } \\
\text { PAGE } 7\end{array}$ \\
\hline $\begin{array}{l}\text { Risk of bias in } \\
\text { individual studies }\end{array}$ & 14 & $\begin{array}{l}\text { Describe anticipated methods for assessing risk of bias of individual studies, } \\
\text { including whether this will be done at the outcome or study level, or both; state } \\
\text { how this information will be used in data synthesis } \\
\text { PAGE 6-7 }\end{array}$ \\
\hline \multirow[t]{4}{*}{ Data synthesis } & $15 a$ & $\begin{array}{l}\text { Describe criteria under which study data will be quantitatively synthesised } \\
\text { PAGE 7-8 }\end{array}$ \\
\hline & $15 b$ & $\begin{array}{l}\text { If data are appropriate for quantitative synthesis, describe planned summary } \\
\text { measures, methods of handling data and methods of combining data from } \\
\text { studies, including any planned exploration of consistency (such as } \text { I }^{2}, \text { Kendall's } \tau \text { ) } \\
\text { PAGE 7-8 }\end{array}$ \\
\hline & $15 c$ & $\begin{array}{l}\text { Describe any proposed additional analyses (such as sensitivity or subgroup } \\
\text { analyses, meta-regression) } \\
\text { PAGE 7-8 }\end{array}$ \\
\hline & $15 d$ & $\begin{array}{l}\text { If quantitative synthesis is not appropriate, describe the type of summary } \\
\text { planned } \\
\text { PAGE 7-8 }\end{array}$ \\
\hline Meta-bias(es) & 16 & $\begin{array}{l}\text { Specify any planned assessment of meta-bias(es) (such as publication bias across } \\
\text { studies, selective reporting within studies) }\end{array}$ \\
\hline $\begin{array}{l}\text { Confidence in } \\
\text { cumulative evidence }\end{array}$ & 17 & $\begin{array}{l}\text { Describe how the strength of the body of evidence will be assessed (such as } \\
\text { GRADE) } \\
\text { PAGE 8-9 }\end{array}$ \\
\hline
\end{tabular}




\section{Appendix II: Search Strategy}

Ovid MEDLINE(R) ALL <1946 to October 05, 2021>

1 aged.mp. or exp Aged/

2 exp Aging/ or aging.mp.

$3 \quad$ ageing.mp. 48503

4 (elder* or geriatric*).mp.

$5 \quad$ senior*.mp. 45480

$6 \quad$ older*.mp. 481495

$7 \quad 1$ or 2 or 3 or 4 or 5 or 6

8 (("high intensity" or interval or circuit) adj3 (training or exercis* or workout)).mp.

[mp=title, abstract, original title, name of substance word, subject heading word, floating subheading word, keyword heading word, organism supplementary concept word, protocol supplementary concept word, rare disease supplementary concept word, unique identifier, synonyms]

9 exp High-Intensity Interval Training/ or HIIT.mp.

10 exp Circuit-Based Exercise/

118 or 9 or 10

12 exp Resistance Training/ or exp Weight Lifting/

13 ((functional or resistance or strength or weight) adj3 (training or exercis* or workout or lifting)).mp. [mp=title, abstract, original title, name of substance word, subject heading word, floating sub-heading word, keyword heading word, organism supplementary concept word, protocol supplementary concept word, rare disease supplementary concept word, unique identifier, synonyms]

1412 or 13

$15 \quad 7$ and 11 and 14 
medRxiv preprint doi: https://doi.org/10.1101/2022.02.10.22270669; this version posted February 10,2022 . The copyright holder for this preprint (which was not certified by peer review) is the author/funder, who has granted medRxiv a license to display the preprint in perpetuity.

All rights reserved. No reuse allowed without permission.

\section{Appendix III: Sample data extraction tables}

Study Characteristics

\begin{tabular}{|l|l|l|l|l|l|l|l|l|}
\hline $\begin{array}{l}\text { Author } \\
\text { (year) }\end{array}$ & Country & $\begin{array}{l}\text { Study } \\
\text { Design }\end{array}$ & Funding & $\begin{array}{l}\text { Clinical Trial } \\
\text { Registration }\end{array}$ & Purpose/Question & $\begin{array}{l}\text { Participant } \\
\text { Inclusion/Exclusion } \\
\text { criteria }\end{array}$ & $\begin{array}{l}\text { Recruitment } \\
\text { method/setting }\end{array}$ & $\begin{array}{l}\text { Baseline sample size } \\
\text { (total: } \\
\text { intervention/control) }\end{array}$ \\
\hline & & & & & & & & \\
\hline
\end{tabular}

\begin{tabular}{|l|l|l|l|}
\hline $\begin{array}{l}\text { Mean age (standard deviation: } \\
\text { SD) total sample }\end{array}$ & Mean age (SD) intervention & Mean age (SD) control $\%$ Male/Female & \\
\hline & & \\
\hline
\end{tabular}

Intervention Details

\begin{tabular}{|l|l|l|l|l|l|l|l|l|}
\hline $\begin{array}{l}\text { Author } \\
\text { (year) }\end{array}$ & $\begin{array}{l}\text { Intervention } \\
\text { title/brief } \\
\text { description }\end{array}$ & $\begin{array}{l}\text { Control } \\
\text { title/brief } \\
\text { description }\end{array}$ & $\begin{array}{l}\text { Intervention } \\
\text { delivery } \\
\text { (who) }\end{array}$ & $\begin{array}{l}\text { Control } \\
\text { delivery } \\
\text { (who) }\end{array}$ & $\begin{array}{l}\text { Intervention } \\
\text { setting }\end{array}$ & $\begin{array}{l}\text { Control } \\
\text { setting }\end{array}$ & $\begin{array}{l}\text { Intervention } \\
\text { overall } \\
\text { duration }\end{array}$ & $\begin{array}{l}\text { Control } \\
\text { overall } \\
\text { duration }\end{array}$ \\
\hline & \\
\hline $\begin{array}{l}\text { Intervention } \\
\begin{array}{l}\text { target } \\
\text { intensity } \\
\text { criteria }\end{array}\end{array}$ & $\begin{array}{l}\text { Control } \\
\text { intensity } \\
\text { criteria }\end{array}$ & $\begin{array}{l}\text { Intervention } \\
\text { session } \\
\text { duration }\end{array}$ & $\begin{array}{l}\text { Control } \\
\text { session } \\
\text { duration }\end{array}$ & $\begin{array}{l}\text { Intervention } \\
\text { format } \\
\text { sets/reps/rest }\end{array}$ & $\begin{array}{l}\text { Control } \\
\text { format }\end{array}$ & $\begin{array}{l}\text { Intervention } \\
\text { description } \\
\text { of specific } \\
\text { exercises }\end{array}$ & $\begin{array}{l}\text { Control } \\
\text { description } \\
\text { of specific } \\
\text { exercises }\end{array}$ & \\
\hline & & & & & & & \\
\hline
\end{tabular}

\section{Results}

\begin{tabular}{|l|l|l|l|l|l|l|l|l|l|}
\hline $\begin{array}{l}\text { Author } \\
\text { (year) }\end{array}$ & $\begin{array}{l}\text { Physical } \\
\text { functioning } \\
\text { outcomes } \\
\text { assessed }\end{array}$ & $\begin{array}{l}\text { Timepoints } \\
\text { assessed }\end{array}$ & Results & $\begin{array}{l}\text { Cognitive } \\
\text { Outcomes } \\
\text { assessed }\end{array}$ & $\begin{array}{l}\text { Timepoints } \\
\text { assessed }\end{array}$ & Results & $\begin{array}{l}\text { Adherence } \\
\text { rates }\end{array}$ & $\begin{array}{l}\text { Retention } \\
\text { (study and } \\
\text { intervention } \\
\text { if available) }\end{array}$ & $\begin{array}{l}\text { Adverse } \\
\text { events }\end{array}$ \\
\hline & & & & & & & & & \\
\hline
\end{tabular}

